\title{
Documentation of the ISA Micro Computed Tomography System
}

\author{
William D. Brown and Jerel A. Smith \\ Lawrence Livermore National Laboratory \\ Livermore, CA 94551 \\ Work performed on the \\ Science \& Technology Directorate of the \\ Department of Homeland Security \\ Statement of Work \\ PR RSEN-08-00066
}

December 18, 2013

Version 1.0

LLNL-TR-649122

IM\# 768047
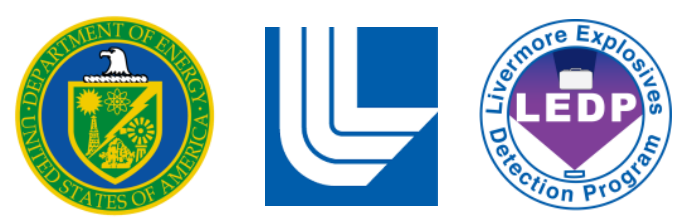
This document was prepared as an account of work sponsored by an agency of the United States government. Neither the United States government nor Lawrence Livermore National Security, LLC, nor any of their employees makes any warranty, expressed or implied, or assumes any legal liability or responsibility for the accuracy, completeness, or usefulness of any information, apparatus, product, or process disclosed, or represents that its use would not infringe privately owned rights. Reference herein to any specific commercial product, process, or service by trade name, trademark, manufacturer, or otherwise does not necessarily constitute or imply its endorsement, recommendation, or favoring by the United States government or Lawrence Livermore National Security, LLC. The views and opinions of authors expressed herein do not necessarily state or reflect those of the United States government or Lawrence Livermore National Security, LLC, and shall not be used for advertising or product endorsement purposes.

This work performed under the auspices of the U.S. Department of Energy by Lawrence Livermore National Laboratory under Contract DE-AC52-07NA27344. 


\section{Table of Contents}

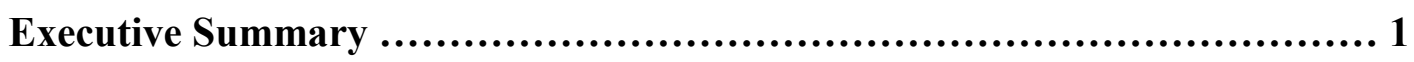

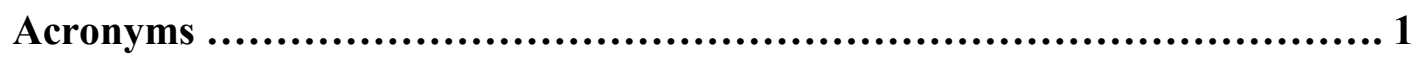

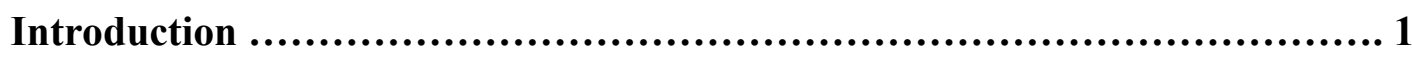

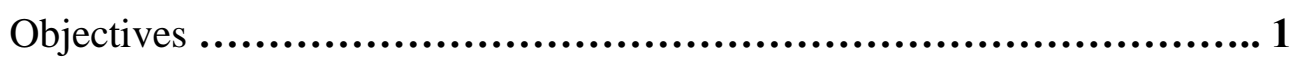

Overview ...............................................................1

MicroCT System Specifications ................................................3

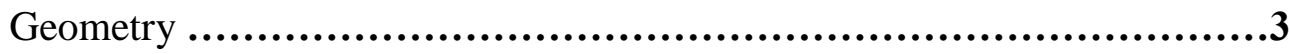

Image-Pixel Dimensions ................................................. 3

X-ray Shielded Cabinet ................................................................................................. 3

Functional Component Documents and Critical Specifications .............. 5

CT Techniques ........................................................7

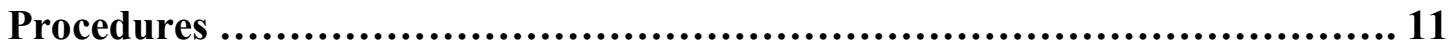

System Alignment ....................................................... 11

X-ray Source Warm-up ................................................. 11

Detector Calibration ........................................................ 11

Data Acquisition ............................................................ 11

References …................................................................ 12

Published Documents ..................................................... 12

Standard Operating Procedures ............................................. 12

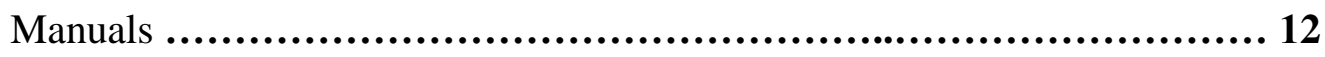

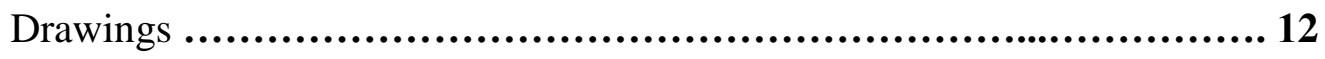

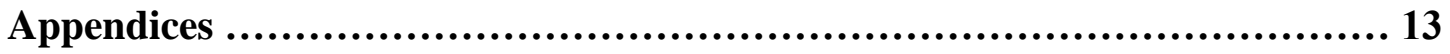

X-Ray Anode Geometry ............................................... 13

MicroCT Carousel Layout ................................................... 14

$\begin{array}{ll}\text { LLNL-TR-XXXXXX } & \text { iii }\end{array}$ 


\section{Documentation of the ISA Micro Computed Tomography System}

\section{Executive Summary:}

This document is intended to provide information on the ISA Micro Computed Tomography (MicroCT) system that will be installed in Yavne, Israel. X-ray source, detector, and motion control hardware are specified as well as specimen platforms, containers, and reference material types. Most of the details on the system are derived from Reference 1 and 2.

\section{Acronyms:}

$\begin{array}{ll}\mathrm{cm} & \text { Centimeter } \\ \mathrm{CT} & \text { Computed Tomography } \\ \mathrm{EDS} & \text { Explosive Detection System } \\ \mathrm{HME} & \text { Homemade Explosive } \\ \mathrm{kV} & \text { Kilovolt } \\ \mathrm{kW} & \text { Kilowatts } \\ \text { LLNL } & \text { Lawrence Livermore National Laboratory } \\ \text { LAC } & \text { Linear Attenuation Coefficient } \\ \text { LDPE } & \text { Low Density Polyethelene } \\ \text { PET } & \text { Polyethylene Terephthalate } \\ \text { ISA } & \text { Israel Security Agency }\end{array}$

\section{Introduction:}

\section{Objectives:}

This document is intended to provide information on a high spatial-resolution computed tomography (MicroCT) scanner. The documentation is intended as a reference to inform users of the MicroCT with those details that are needed to understand and evaluate the system. The documentation will address the hardware components, their physical and functional relationships, the assembly of those components as an imaging system, and the parameters of their usage.

\section{Overview:}

The MicroCT scanner is designed to measure and compare the physical properties of samples in the context of CT imaging. The scanner includes a high-voltage DC x-ray source, an area detector, a positioning system that provides rotation and translation of the sample, a sample-support stage and carousel, and a double-slit collimator.

Samples are supported in a carousel and imaged in two different planes. The upper plane images a single specimen which is the material to be characterized and its container, as needed. The lower plane images a number of known "references" which are used for 
calibration. In both planes, a strip of copper sheet provides a reference for monitoring the stability and consistency of the imaging system. The two-slit collimator projects two multiple slice $\mathrm{x}$-ray fan beams, one through each plane, while minimizing the $\mathrm{x}$-ray scatter from objects not essential to imaging the portion of the samples transected by those fans. The measured fan-beam transmission data are reconstructed as 2-D images.

Images are also made with the upper slit-collimator removed. These images are used either as 2-D radiographs, or reconstructed as 3-D (cone-beam) images.

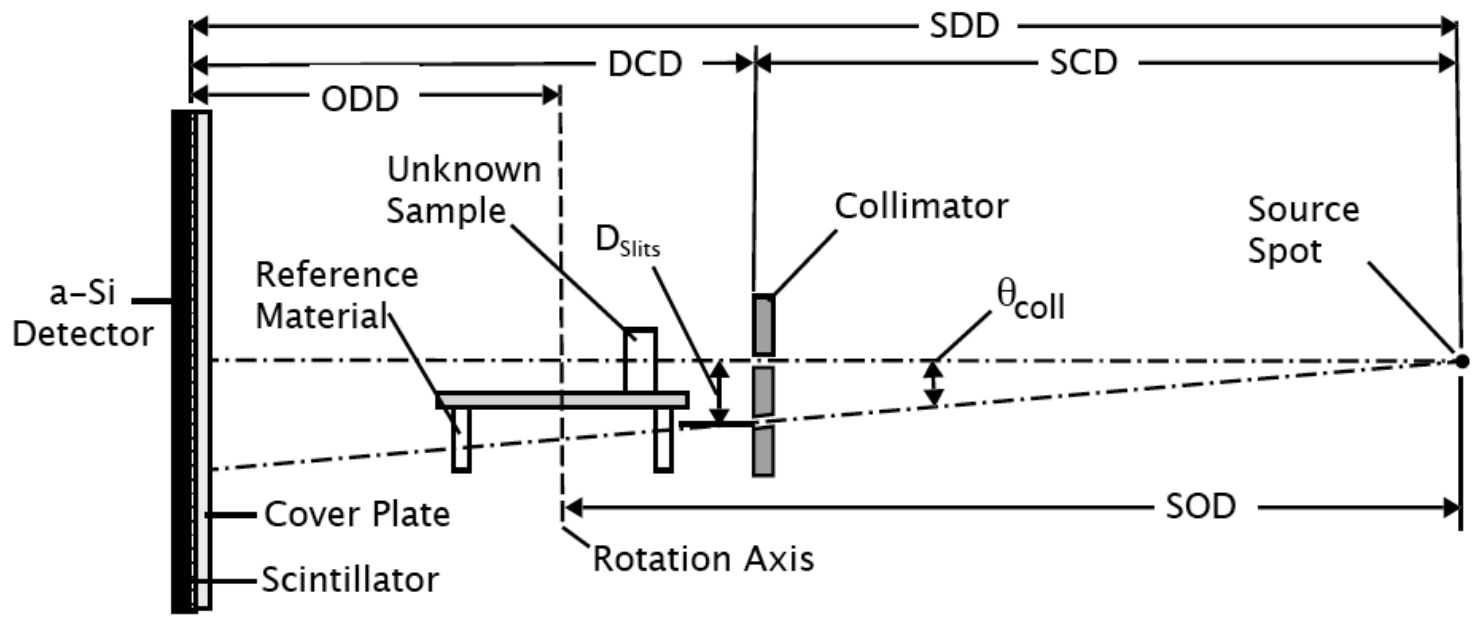

Figure 1. MicroCT System Geometry: Measurements are from the center of the sourcespot, the detector side of the collimator, the rotational center of the table and the active surface of the scintillator. 


\section{MicroCT System Specifications}

Geometry (These are nominal values acquired in April 2013. The values may change slightly after movement of the system, preventative maintenance, and re-alignment of the system)

SDD

ODD

SOD

SCD

$\theta$ coll

D Slits $_{\text {S }}$

Object Magnification

OSD

ORD
$1413.4 \mathrm{~mm}$

$310.9 \mathrm{~mm}$

1102.5

$950 \mathrm{~mm}$

$1.51 \mathrm{deg}$.

$25 \mathrm{~mm}$

1.30

$44.45 \mathrm{~mm}$ Center of rotation to center of specimen

$82.55 \mathrm{~mm}$ Center of rotation to center of references

Image-Pixel Dimensions

Inherent Detector Pixel size

Image Pixel (at center of rotation)
$0.200 \mathrm{~mm}$ X $0.200 \mathrm{~mm}$

$0.156 \mathrm{~mm}$ X $0.156 \mathrm{~mm}$

\section{X-ray Shielded Cabinet}

Shielded Cabinet Drawings:

Shielded Cabinet Wiring Schematic: [D2]

$\mathrm{X}$-ray Interlock Wiring:

[D3] 


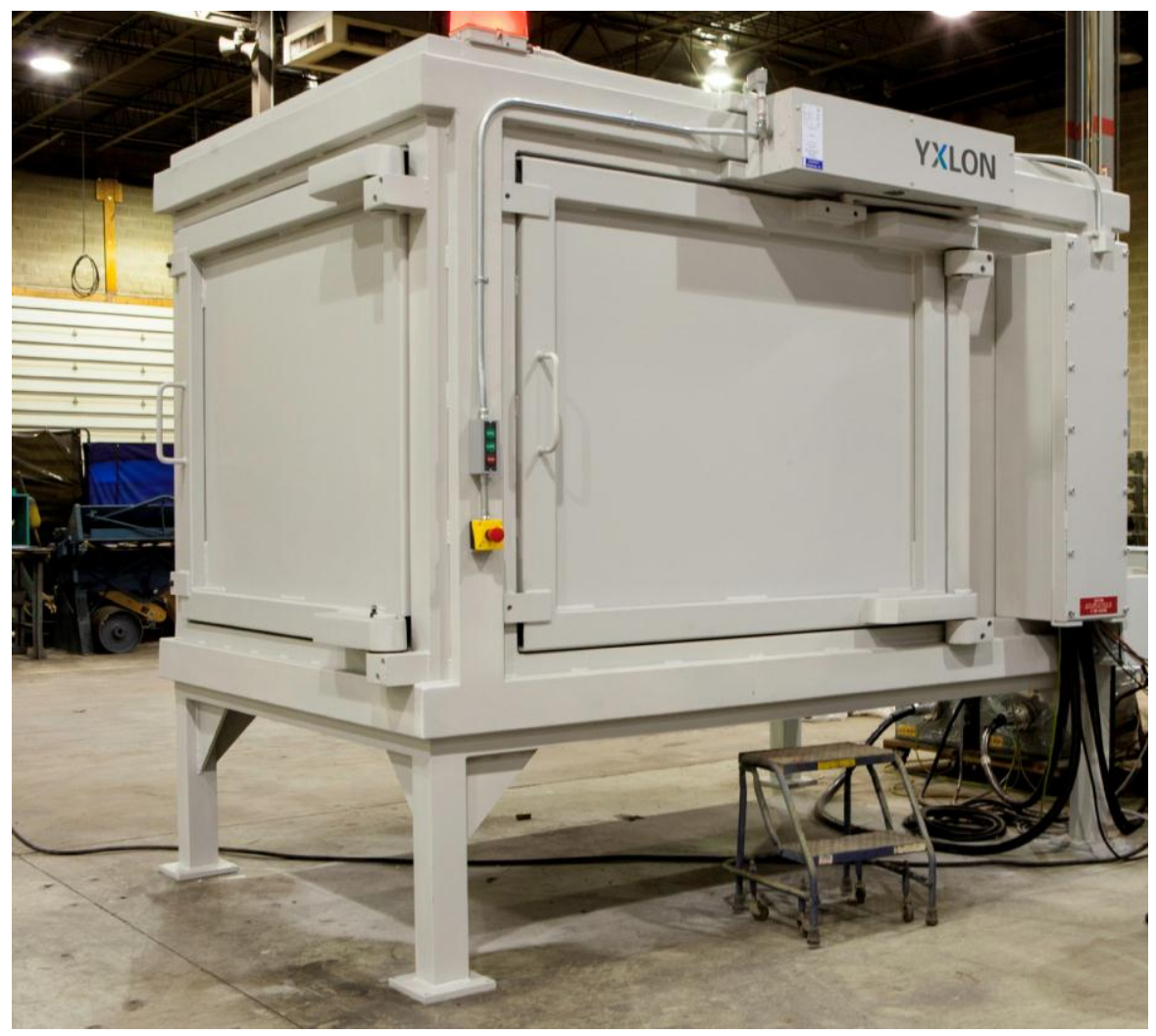

Figure 2: ISA X-ray Shielded System. Front view showing electric door.

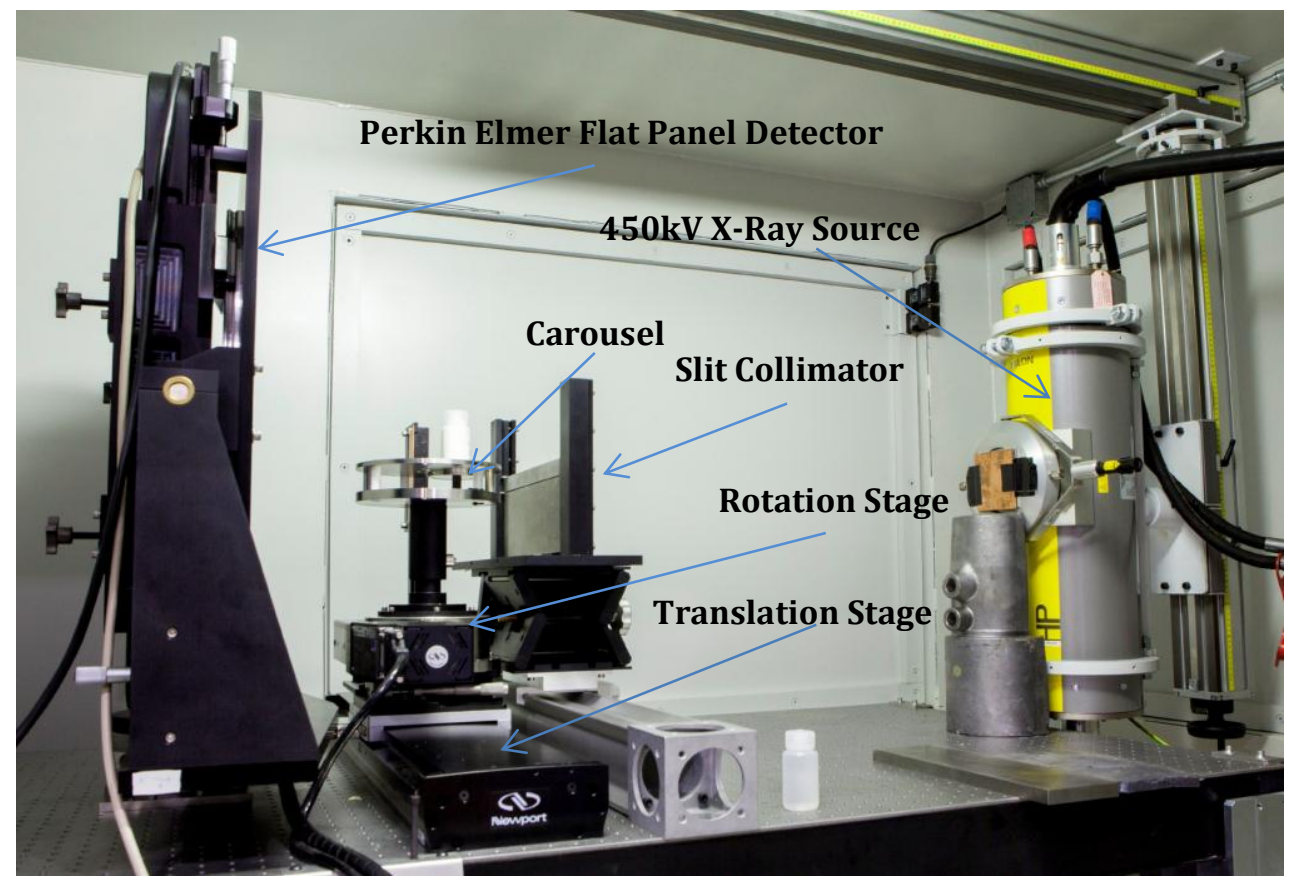

Figure 3: ISA System internal components 
Functional Component Documents and Critical Specifications

X-ray Source Tubehead:

Make:

YXLON

Model:

Y.TU 450-D11

Serial No:

298251

Tube type:

Metal Ceramic

Focal Spot (EN 12543):

$0.4 \mathrm{~mm} / 1.0 \mathrm{~mm}$

Target Material:

Tungsten

Takeoff Angle:

11 degrees; Appendix 1

Anode-Cathode Axis: LLNL

X-ray Window:

Vertical: Anode on top

5-mm Be

HV Potential Range:

20-450 kV

Power (Max):

$0.7 \mathrm{~kW}(0.4-\mathrm{mm}) / 1.5 \mathrm{~kW}(1.0)$

User Manual and Specs:

[M1]

X-ray Source Controller, Power Supply, Generators and Oil Cooler :

Make:

YXLON

Controller Model / SN:

MGC41 / 310392

Power Supply / SN:

MGP41 / 309772

Generator (-) Model / SN

MGG46 / 307769

Generator (+) Model / SN

MGG47 / 306397

Potential (min/max):

Accuracy:

$20 / 450 \mathrm{kV}$

Current (min/max):

$\pm 1 \%$ of demand value $\pm 0.2 \mathrm{kV}$

$0.5 / 15 \mathrm{~mA}$

Accuracy:

$\pm 0.2 \%$ of demand value $\pm 0.01 \mathrm{~mA}$

Max Power:

$1.5 \mathrm{~kW}$

Oil Cooler Model / SN

Manufacturers Specs:

OL-4502 / 2009569002

[M1], [M2]

Collimator:

Material:

$15.9 \mathrm{~mm}$ thick tungsten

Slit Separation $\left(\mathrm{D}_{\text {slits }}\right)$

$25.0 \mathrm{~mm}$ (center to center, source side)

Slit Width

$2.0 \mathrm{~mm}$ (set by shim)

Slit Length:

$330.2 \mathrm{~mm}$

Collimator Drawings:

[D4]

Sample-Position Controller and Stages:

Make:

Newport

Controller Model / SN:

Controller User Manual:

XPS / 12154031

Trans Stage Model/SN:

[M3]

Trans Stage User Manual:

IMS600LM/B12 1619

Rotary Stage Model/SN:

[M4]

Rotary Stage User Manual:

RV160PP/B11 10038

[M5] 
Detector:

Make: $\quad$ Perkin Elmer

Type: $\quad$ Flat Panel AmSi 2D Array

Model No: $\quad$ XRD 1620 AN14 CS

Serial No: $\quad 380-6286$

Front Panel: $\quad 0.75 \mathrm{~mm} \mathrm{Al}$ and $0.52 \mathrm{~mm}$ Graphite

Scintillator: $\quad$ DRZ Plus $\left(\mathrm{Gd}_{2} \mathrm{O}_{2} \mathrm{~S}: \mathrm{Tb}\right)$

Detector User Manual: [M6]

\begin{tabular}{|c|c|c|c|}
\hline & Protective Layer & Phosphor Layer & Suppoprting Layer \\
\hline DRZ-Plus & PET $6 \mu \mathrm{m}$ & $208 \mu \mathrm{m}, 100 \mathrm{mg} / \mathrm{cm}^{2}$ & Plastic Base $250 \mu \mathrm{m}$ \\
\hline
\end{tabular}

Table 1: Scintillator components and thicknesses.

Energy Monitoring Cu Strip: $\quad 99.9+\%$ Copper;

$25.4 \mathrm{~mm}$ X $101.5 \mathrm{~mm}$ X $1.25 \mathrm{~mm}$ Thick

Data Acquisition Computer:

$\begin{array}{ll}\text { Make: } & \text { Dell } \\ \text { Model: } & \text { D09M } \\ \text { Serial No: } & \text { 58RD8V1 } \\ \text { Operating System: } & \text { Windows }^{\text {TM }} 7\end{array}$

Image Processing and Reconstruction Computer:

Make: Dell

Model: $\quad$ D09M

Serial No: $\quad$ 58SF8V1

Operating System: $\quad$ Windows ${ }^{\mathrm{TM}} 7$

12.7 mm Diameter Carousel References (Purity/Density g/ $\mathrm{cm}^{3}$ )

Delrin $100 \mathrm{NC010/1.404}$

Teflon 60x Series/2.173

Graphite 99.99+\%/1.804

Magnesium $\quad 99.95+\% / 1.734$

Water > $\quad 99.9999 \%$

Silicon $\quad 99.999 \% / 2.330$

Container for Water Reference

Material:

Polypropylene

OD/ID: $\quad 14.0 \mathrm{~mm} / 10.8 \mathrm{~mm}$

Sample Container

Manufacturer:

Part No:

Material:

Fisher Scientific - www.Fishersci.com

Capacity:

02-896-1B

LDPE

$60 \mathrm{ml}$ 
Sample/Material Positions:

Sample Carousel Design:

Filters (Type/Thickness/Purity):
Appendix 2

[D5]

Aluminum/2.0mm/ 99.99\%

Copper/2.0 mm/99.9+\%

\section{CT Techniques:}




\begin{tabular}{|c|c|}
\hline System Information & \\
\hline Data Acquistion Date & Monday, April 22, 2013 \\
\hline System & ISA 450kV \\
\hline Archive Directory & C:IISA System\CT Data\QA_Acq \\
\hline \multicolumn{2}{|l|}{ Source } \\
\hline X-ray Source & Yxlon 450kV D11 \\
\hline Effective Spot Size $(\mathrm{mm})$ & Small 0.4 \\
\hline Energy $(\mathrm{kV})$ & 160 \\
\hline Tube Current (mA) & 4.35 \\
\hline Geometric Unsharpness (mm) & 0.113 \\
\hline Filter (Type/Thickness mm) & $\mathrm{Al} / 2.0 \mathrm{Cu} / 2.0$ \\
\hline \multicolumn{2}{|l|}{ Detector } \\
\hline Detector Type & Amorphous Silicon Perkin Elmer \\
\hline Source-Detector-Distance (SDD) (mm) & 1413.4 \\
\hline Source-Object-Distance (SOD) (mm) & 1102.52 \\
\hline Object-Detector-Distance (ODD) $(\mathrm{mm})$ & 310.88 \\
\hline X-Offset (Pixels) & 309 \\
\hline X-Size (Pixels) & 1698 \\
\hline Y-Offset (Pixels) & 1040 \\
\hline Y-Size (Pixels) & 235 \\
\hline Magnification & 1.282 \\
\hline Frame Average(s) & 6 \\
\hline Integration Knob-Thales Only & $\mathrm{N} / \mathrm{A}$ \\
\hline Integration Time per Frame(sec) & 1.15 \\
\hline Raw Pixel Size $(\mathrm{mm})$ & 0.2 \\
\hline Global Resampling & 1 \\
\hline Effective Pixel size at Detector (mm) & 0.2 \\
\hline Effective Pixel size at Object $(\mathrm{mm})$ & 0.156 \\
\hline \multicolumn{2}{|l|}{ CT Parameters } \\
\hline Numbers of Views & 401 \\
\hline Angular Range & 200.5 \\
\hline Angular Step (Degrees) & 0.5 \\
\hline Estimated PxCenterFull Panel (Pixel) & 1022.7 \\
\hline Estimated PzCenterFull Panel (Pixel) & 1061.7 \\
\hline
\end{tabular}

Table 2: CT Technique for $160 \mathrm{kV} 2$ Slit (exp1) Data 


\begin{tabular}{|c|c|}
\hline \multicolumn{2}{|l|}{ System Information } \\
\hline Data Acquistion Date & Monday, April 22, 2013 \\
\hline System & ISA 450kV \\
\hline Archive Directory & C: \ISA System\CT Data\QA_Acq \\
\hline \multicolumn{2}{|l|}{ Source } \\
\hline X-ray Source & Yxlon 450kV D11 \\
\hline Effective Spot Size (mm) & Small 0.4 \\
\hline Energy (kV) & 100 \\
\hline Tube Current (mA) & 7 \\
\hline Geometric Unsharpness (mm) & 0.113 \\
\hline Filter (Type/Thickness mm) & $\mathrm{Al} / 2.0$ \\
\hline \multicolumn{2}{|l|}{ Detector } \\
\hline Detector Type & Amorphous Silicon Perkin Elmer \\
\hline Source-Detector-Distance (SDD) (mm) & 1413.4 \\
\hline Source-Object-Distance (SOD) (mm) & 1102.52 \\
\hline Object-Detector-Distance (ODD) (mm) & 310.88 \\
\hline X-Offset (Pixels) & 309 \\
\hline X-Size (Pixels) & 1698 \\
\hline Y-Offset (Pixels) & 1040 \\
\hline Y-Size (Pixels) & 235 \\
\hline Magnification & 1.282 \\
\hline Frame Average(s) & 6 \\
\hline Integration Knob-Thales Only & N/A \\
\hline Integration Time per Frame(sec) & 0.267 \\
\hline Raw Pixel Size $(\mathrm{mm})$ & 0.2 \\
\hline Global Resampling & 1 \\
\hline Effective Pixel size at Detector (mm) & 0.2 \\
\hline Effective Pixel size at Object (mm) & 0.156 \\
\hline \multicolumn{2}{|l|}{ CT Parameters } \\
\hline Numbers of Views & 401 \\
\hline Angular Range & 200.5 \\
\hline Angular Step (Degrees) & 0.5 \\
\hline Estimated PxCenterFull Panel (Pixel) & 1022.7 \\
\hline Estimated PzCenterFull Panel (Pixel) & 1061.7 \\
\hline
\end{tabular}

Table 3: CT Technique for $100 \mathrm{kV} 2$ Slit (exp2) Data 


\begin{tabular}{|c|c|}
\hline \multicolumn{2}{|l|}{ System Information } \\
\hline Data Acquistion Date & Monday, April 22, 2013 \\
\hline System & ISA 450kV \\
\hline Archive Directory & C:\ISA System\CT Data\QA Acq \\
\hline \multicolumn{2}{|l|}{ Source } \\
\hline X-ray Source & Yxlon 450kV D11 \\
\hline Effective Spot Size (mm) & Small 0.4 \\
\hline Energy (kV) & 160 \\
\hline Tube Curren $\mathrm{t}(\mathrm{mA})$ & 4.35 \\
\hline Geometric Unsharpness (mm) & 0.113 \\
\hline Filter (Type/Thickness mm) & $\mathrm{Al} / 2.0 \mathrm{Cu} / 2.0$ \\
\hline \multicolumn{2}{|l|}{ Detector } \\
\hline Detector Type & Amorphous Silicon Perkin Elmer \\
\hline Source-Detector-Distance (SDD) (mm) & 1413.4 \\
\hline Source-Object-Distance (SOD) (mm) & 1102.52 \\
\hline Object-Detector-Distance (ODD) (mm) & 312.4 \\
\hline X-Offset (Pixels) & 309 \\
\hline X-Size (Pixels) & 1698 \\
\hline Y-Offset (Pixels) & 606 \\
\hline Y-Size (Pixels) & 669 \\
\hline Magnification & 1.282 \\
\hline Frame Average(s) & 6 \\
\hline Integration Knob-Thales Only & N/A \\
\hline Integration Time per Projection(sec) & 0.267 \\
\hline Raw Pixel Size $(\mathrm{mm})$ & 0.2 \\
\hline Global Resampling & 1 \\
\hline Effective Pixel size at Detector $(\mathrm{mm})$ & 0.2 \\
\hline Effective Pixel size at Object (mm) & 0.156 \\
\hline \multicolumn{2}{|l|}{ CT Parameters } \\
\hline Numbers of Views & 401 \\
\hline Angular Range & 200.5 \\
\hline Angular Step (Degrees) & 0.5 \\
\hline Estimated PxCenterFull Panel (Pixel) & 1022.7 \\
\hline Estimated PzCenterFull Panel (Pixel) & 1061.7 \\
\hline
\end{tabular}

Table 4: CT Technique for 160 kV 1 Slit (exp1_Open) Data 


\section{Procedures}

System Alignment

Alignment of the detector panel to the tube head and determination of the beam center are described in Reference [SO].

\section{X-ray Source Warm-up}

$\mathrm{X}$-ray source warm-up procedures follow the directions in the X-ray source user manual [M1].

Detector Calibration

Detector calibration procedures follow the manufacturer's instructions provided in the detector user manual [M6].

Data Acquisition

The data acquisition procedures are laid out in Reference 1. The detailed steps used for LLNL micro-CT scans are documented in Reference [S1]. 


\section{References}

\section{Published Documents}

1. Brown, WD, TPXX - Data Collection and Image Reconstruction using the ISA MicroCT System, LLNL-TR-XXXXXX, December 18, 2013.

2. Smith, JA, D. Schneberk, J. Kallman, H. Martz, Jr., D. Hoey, R. Krauss, R. Klueg, Documentation of the LLNL, TAFB and TSL Micro-Computed-

Tomography Systems, LLNL-TR-421377 Revision 1, November 30, 2011

\section{Standard Operating Procedures}

S0 Divin, CJ, MicroCT: Procedure for Alignment, Lawrence Livermore National Laboratory, LEDP-MCT-SOP-010, March 14, 2013

S1 Pincus, C, MicroCT Data Acquisition Checklist, Lawrence Livermore National Laboratory, LLNL-TR-XXXXXX, May 1, 2013

Manuals (Manuals can be located in the ISA MicroCT Manual)

M1: UM_MG103_452 10IG15.pdf

M2: OL 4502 Yxlon New.pdf

M3: Newport XPS-C6 Users Manual.pdf

M4: Newport IMS-LM Series Linear Motor Stages_08-11.pdf

M5: Newport RV Users Manual

M6: Perkin Elmer Flat Panel Users Manual

\section{Drawings (Drawings can be located in the ISA MicroCT Manual)}

D1: Shielded Cabinet Drawings

D2: Shielded Cabinet Wiring Schematic

D3: X-ray Interlock Wiring Schematic

D4: Slit Collimator Drawings

D5: MicroCT Universal Carousel System.pdf 


\section{Appendices}

\section{Appendix 1: X-ray Anode Geometry}

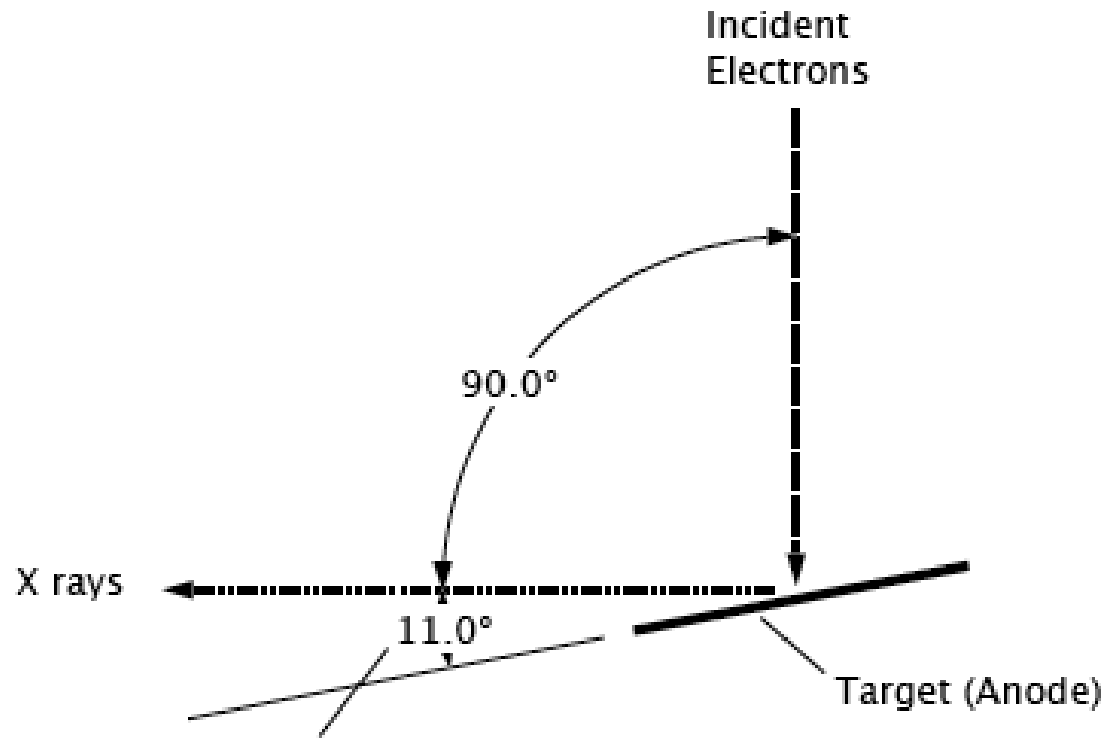

Takeoff Angle

Figure 1A. The geometry of the x-ray target and the definition of "Takeoff Angle" are shown. The vector marking the exit path of the x rays, defines the "central ray" of the CT system. System alignment sets this ray normal to the surface of the detector and locates the position (row and column) of incidence. 


\section{Appendix 2: MicroCT Carousel Layout}

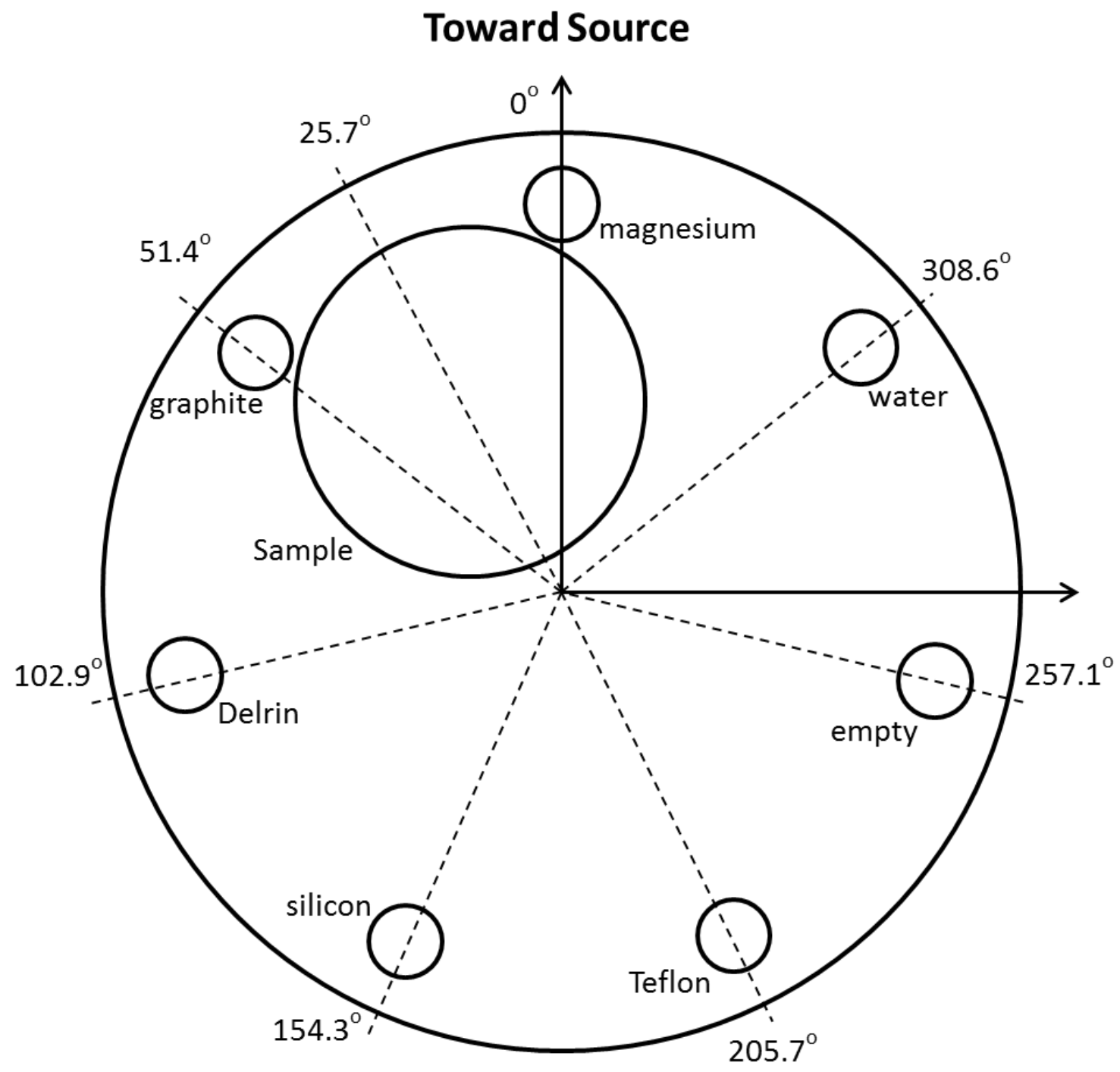

Figure 2A. Sample carousel. The carousel is viewed from above in the initial position and rotates clockwise 